\title{
Preparation of UHPC with cement replaced by rich-silicon iron ore tailing
}

\section{powder $^{1}$}

\section{Lin YANG}

CCCC Wuhan Harbour Engineering Design And Research Co., Ltd, Wuhan, 430040, China. Hubei Key Laboratory of Advanced Materials \& Reinforcement Technology Research for Marine En vironment Structures. Wuhan, Hubei 430040, China.

Keywords: IOTP; UHPC; strength; pore structure; hydration products morphology

Abstract: In order to study the influence rule and mechanism of iron ore tailing powder(IOTP) replacing cement in UHPC, the influences of different specific surface area and dosage of IOTP replacing cement on its strength and liquidity were tested. Moreover, the pore structure and hydration products morphology of UHPC were tested by MIP and SEM, respectively. The results show that IOTP can increase the liquidity of UHPC, when alternative content of IOTP is less than $10 \%$, proper specific surface area of IOTP can improve the strength, pore structure and hydration products structure of UHPC. However, when alternative content of IOTP is more than $15 \%$, it shows up an inverse pattern.

\section{Introduction}

IOT is the major component of industrial solid waste. According to incomplete statistics, there are more than 10 billion tons of ore tailing discharged around the world every year, the stock of ore tailing in China is more than 10 billion tons and nearly one half is IOT. However, it is growing at a rate of 500 million tons every year ${ }^{[1]}$. The stored IOT causes many sorts of environmental pollution, moreover, some IOT ponds are at risk of dam break ${ }^{[2-5]}$.

Wen NI found a certain amount of IOTP could improve the porosity of composite gelled material and lower the proportion of big pore ${ }^{[6]}$. Xueying MA through test showed IOTP after mixed with slag powder could improve the working performance, mechanical property and durability of the concrete $^{[7]}$. Beixing LI found the rich-silicon IOTP mainly played a physical filling effect in concrete after curing in $90^{\circ} \mathrm{C}$ water ${ }^{[8]}$. The research of Xiaoyan HUANG showed IOTP used as mineral admixtures preparation high ductility fiber reinforced cement matrix composites was feasible, under the same mineral admixture content, the strength of IOTP ECC performance was lower than the fly ash ECC, but showed a stronger tensile ductility ${ }^{[9]}$.

UHPC as a new type of building materials, with its excellent performance has attracted much attention, many scholars have carried out a lot of study about UHPC. Results show that porosity of UHPC is very low, inner structure is compact, but poor workability ${ }^{[10-15]}$. Combining with its high production cost and consistency, IOT is difficult to deal and has certain activity, the research tries to prepare UHPC with IOTP replacing cement, and explores its influences on the strength, liquidity, hydration products and pore structure of UHPC.

1 Author:Lin Yang, senior engineer. Email: 312378964@qq.com Tel:15377678112. 


\section{Experimental}

\section{Materials}

(1) The 52.5 ordinary Portland cement is from Huaxin, its physical properties and chemical composition are shown in table 2 and table 3. The IOT is from Miyun area, its main chemical composition is $\mathrm{SiO} 2$ and it belongs to rich-silicon IOT, the main mineral composition are quartz, feldspar minerals and magnetite, all of them are shown in table1, table 2 and figure 1 . The $\mathrm{SiO} 2$ content of inert quartz sand is more than $90 \%$. The water is tap water from Wuhan city. Grinding agent is melamine and quality content is $0.035 \%$.

(2) Fly ash, specific gravity is $2.36 \mathrm{~g} / \mathrm{cm} 2$, specific surface area is $7200 \mathrm{~cm} 2 / \mathrm{g}$, water requirement ratio is $93 \%$. white beads, particle size distribution is $0.1 \mu \mathrm{m} \sim 5 \mu \mathrm{m}$, natural state of apparent density is $0.67 \mathrm{~g} / \mathrm{cm} 3$. Gray silicon ash, specific surface area is $22.4 \mathrm{~cm} 2 / \mathrm{g}$, the average particle size is $0.2 \mu \mathrm{m}$, water requirement ratio is about $113 \%$. Their components are shown in table 2. Cylindrical copper coated steel fiber, the diameter is $0.2 \mathrm{~mm}$, length is $12 \mathrm{~mm}$ to $14 \mathrm{~mm}$, tensile strength is $2900 \mathrm{MPa}$, the elastic modulus is $200 \mathrm{GPa}$, density is $7.8 \mathrm{~g} / \mathrm{cm} 3$. Liquid poly carboxylic acid water reducing agent and its water reducing rate is about $30 \%$.

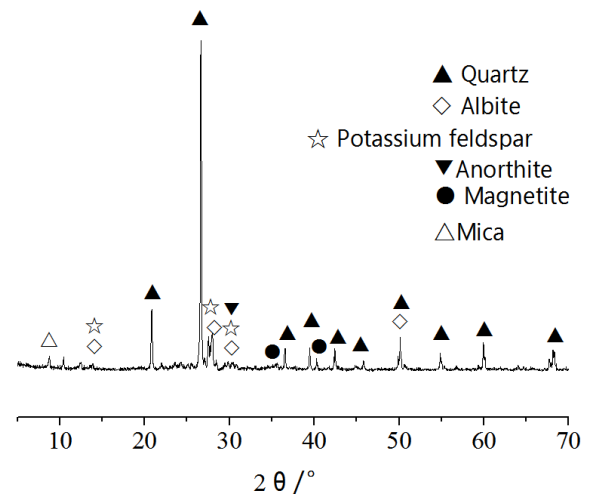

Fig 1 The XRD pattern of IOT

Table 1 Particle size distribution data of IOTP

\begin{tabular}{cccccccc}
\hline $\begin{array}{c}\text { Specific surface } \\
\text { area } / \mathrm{m}^{2} \cdot \mathrm{kg}^{-1}\end{array}$ & $\begin{array}{c}<1 \mathrm{um} \\
1 \%\end{array}$ & $\begin{array}{c}1-10 \\
\mu \mathrm{m} / \%\end{array}$ & $\begin{array}{c}10-30.2 \\
\mu \mathrm{m} / \%\end{array}$ & $\begin{array}{c}>30.2 \\
\mu \mathrm{m} / \%\end{array}$ & $\begin{array}{c}\mathrm{D}_{10} / \\
\mu \mathrm{m}\end{array}$ & $\begin{array}{c}\mathrm{D}_{50} / \\
\mu \mathrm{m}\end{array}$ & $\begin{array}{c}\mathrm{D}_{90} / \\
\mu \mathrm{m}\end{array}$ \\
\hline 394 & 3.93 & 39.74 & 32.82 & 23.51 & 1.403 & 12.611 & 49.906 \\
588 & 6.64 & 41.65 & 30.23 & 21.48 & 1.257 & 10.755 & 47.515 \\
801 & 7.50 & 44.02 & 29.27 & 19.01 & 1.150 & 9.273 & 44.122 \\
1013 & 8.78 & 45.06 & 27.62 & 18.00 & 1.037 & 8.171 & 42.756 \\
\hline
\end{tabular}

Table 2 The basic physical properties of cement

\begin{tabular}{cccccccccc}
\hline \multirow{2}{*}{$\begin{array}{c}\text { Water requirement of } \\
\text { Normal consistency/\% }\end{array}$} & Setting time/min & \multicolumn{3}{c}{$\begin{array}{c}\text { Compressive } \\
\text { strength/MPa }\end{array}$} & \multicolumn{3}{c}{ Flexural strength /MPa } \\
\cline { 2 - 9 } & Initial & Fianl & $3 \mathrm{~d}$ & $7 \mathrm{~d}$ & $28 \mathrm{~d}$ & $3 \mathrm{~d}$ & $7 \mathrm{~d}$ & $28 \mathrm{~d}$ \\
\hline 27.6 & 104 & 176 & 30.0 & 48.5 & 55.2 & 5.7 & 8.8 & 9.5 \\
\hline
\end{tabular}


Table 3 The chemical composition of cement and IOT $(\%)$

\begin{tabular}{cccccccccc}
\hline Name & $\mathrm{SiO}_{2}$ & $\mathrm{Al}_{2} \mathrm{O}_{3}$ & $\mathrm{Fe}_{2} \mathrm{O}_{3}$ & $\mathrm{MgO}$ & $\mathrm{CaO}$ & $\mathrm{SO}_{3}$ & $\mathrm{Na}_{2} \mathrm{O}$ & $\mathrm{K}_{2} \mathrm{O}$ & Loss \\
\hline Cement & 19.95 & 5.06 & 3.34 & 2.54 & 63.30 & 2.29 & 0.14 & 0.53 & 1.09 \\
IOT & 65.27 & 7.46 & 11.80 & 5.27 & 3.80 & 0.24 & $/$ & $/$ & 2.13 \\
Fly ash & 55.77 & 31.77 & 3.88 & 0.61 & 2.59 & 0.60 & $/$ & $/$ & 1.03 \\
Bead & 60.21 & 15.92 & 8.02 & 2.41 & 6.04 & 0.37 & $/$ & $/$ & 0.19 \\
Silicon ash & 94.32 & 0.14 & 1.29 & 0.05 & 0.06 & 0.43 & $/$ & $/$ & 3.40 \\
\hline
\end{tabular}

\section{UHPC mortars preparation}

The mortars moulded at $100 \mathrm{~mm} \times 100 \mathrm{~mm} \times 100 \mathrm{~mm}, 100 \mathrm{~mm} \times 100 \mathrm{~mm} \times 400 \mathrm{~mm}$ molds, room temperature should be kept at $20 \pm 2^{\circ} \mathrm{C}$, relative humidity should be not less than $50 \%$, then the forms are removed after $1 \mathrm{~d}$, specimen are putted into water heated to $90{ }^{\circ} \mathrm{C}$ for $48 \mathrm{~h}$ (temperature $15^{\circ} \mathrm{C} / \mathrm{h}$ or less), and then blocked in the oven which temperature was $20 \pm 2^{\circ} \mathrm{C}$, relative humidity were more than $90 \%$ cured to certain age. Table 4 is the the mix of UHPC.

Table 4 Mix of blank UHPC

\begin{tabular}{ccccccc}
\hline \multirow{2}{*}{$\begin{array}{c}\text { Water-binder } \\
\text { ratio }\end{array}$} & \multirow{2}{*}{ Binder-sand } & \multicolumn{5}{c}{ Binding materials } \\
\cline { 3 - 6 } & ratio & Cement & Bead & Fly ash & Silicon ash & Water reducer \\
\hline 0.16 & $1: 1$ & $60 \%$ & $15 \%$ & $15 \%$ & $10 \%$ & $1.5 \%$ \\
\hline
\end{tabular}

Note: copper coated steel fiber volume content is $2.0 \%$.

\section{Characterization}

The model of SEM equipment is JSM-5610LV and made by Japanese Electronics Corporation. Samples preparation method: samples are from center area of mortars and hydration stopped by anhydrous ethanol, samples are dried in $40^{\circ} \mathrm{C}$ condition till to constant weight. The pore structure is tested by Autopore III9420 made by America, measuring range is $0.003 \mathrm{um} \mathrm{360um,} \mathrm{maximum}$ working pressure is $414 \mathrm{MPa}$. Samples preparation method: samples are from center area, hydration stopped by anhydrous ethanol and dried in the condition below $90^{\circ} \mathrm{C}$ till to constant weight before test.

\section{Results and discussion}

\section{Strength}

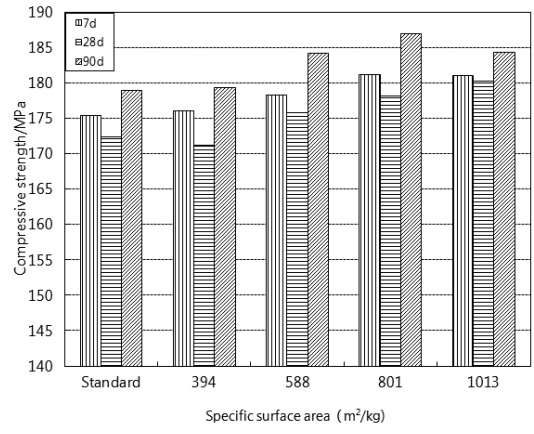

(a) $5 \%$

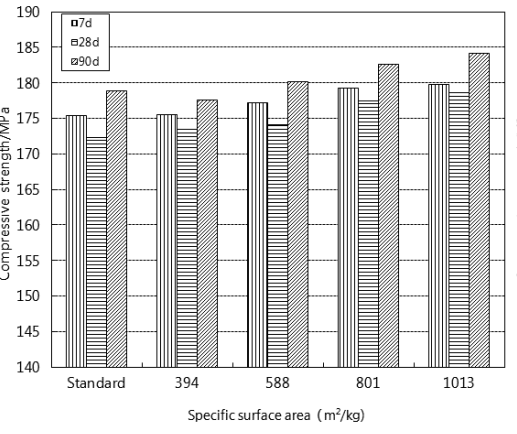

(b) $10 \%$

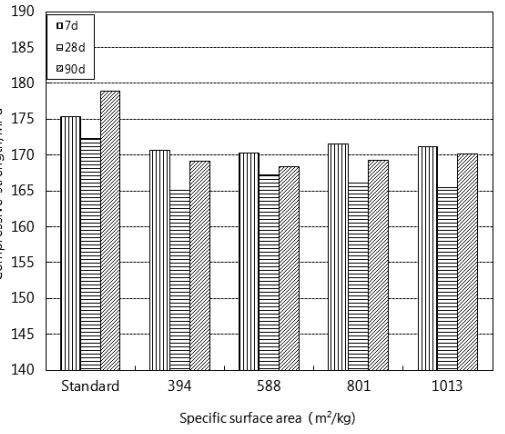

(c) $15 \%$

Fig.2 The influence of IOTP content on strength 
Figure 2 is about the influences of different specific surface area and content of IOTP to replace cement on the $7 \mathrm{~d}, 28 \mathrm{~d}$ and $90 \mathrm{~d}$ strength.

From figure (a) can be known: when IOTP specific surface area was $394 \mathrm{~m} 2 / \mathrm{kg}$, the strength of UHPC almost did not change, when the IOTP specific surface area continued growing, the strength of UHPC appeared different degree of growth, and it reached the top value when the specific surface area of IOTP was $801 \mathrm{~m} 2 / \mathrm{kg}$ (except the $28 \mathrm{~d}$ strength value). For $7 \mathrm{~d}$ strength, four different specific surface area of IOTP, change value compared with standard sample was $0.72 \mathrm{MPa}, 2.88 \mathrm{MPa}$, $5.75 \mathrm{MPa}$ and $5.56 \mathrm{MPa}$, respectively. For $28 \mathrm{~d}$ strength, the change value was $-0.90 \mathrm{MPa}, 3.42 \mathrm{MPa}$, 5.79MPa and 7.90MPa, respectively. For $90 \mathrm{~d}$ strength, the change value was $0.43 \mathrm{MPa}, 5.33 \mathrm{MPa}$, 8.01MPa and 5.42MPa, respectively. It was visible that when IOTP content was $5 \%$, the impact of IOTP specific surface area on the strength was more obvious.

From figure (b) can be known: when IOTP specific surface area was $394 \mathrm{~m} 2 / \mathrm{kg}$, the strength of UHPC showed a little bit, but it appeared growing with the growth of IOTP specific surface area. The biggest change value of $7 \mathrm{~d}, 28 \mathrm{~d}$ and $90 \mathrm{~d}$ strength was $4.30 \mathrm{MPa}, 6.34 \mathrm{MPa}$ and $5.23 \mathrm{MPa}$, respectively. And it showed that the rate of contribution was inferior to when the IOTP content was $5 \%$.

From figure (c) can be known: when the replacing content was $15 \%$, the strength of UHPC decreased significantly and the influence of specific surface area was tiny. This may be because too much IOTP lead to lack of cement, the hydration products were hard to package aggregate, and the inner structure was not impact, all of these factors would greatly influenced the macroscopic strength.

\section{Fluidity}

Table 5 The influence of cement replacement content on jump table fluidity

\begin{tabular}{ccccc}
\hline IOTP content & \multicolumn{4}{c}{ Jump table fluidity(mm) } \\
\cline { 2 - 4 }$(\%)$ & $394 \mathrm{~m}^{2} / \mathrm{kg}$ & $588 \mathrm{~m}^{2} / \mathrm{kg}$ & $801 \mathrm{~m}^{2} / \mathrm{kg}$ & $1013 \mathrm{~m}^{2} / \mathrm{kg}$ \\
\hline 0 & 190 & 190 & 190 & 190 \\
5 & 198 & 207 & 201 & 195 \\
10 & 220 & 227 & 220 & 213 \\
15 & 254 & 260 & 256 & 248 \\
\hline
\end{tabular}

Table 5 was about the influence of cement replacement content on jump table fluidity. From it we could see that when the specific surface area was the same, the jump table fluidity increased with the growth of IOTP replacing content. We also could see that when the IOTP content was the same, the jump table fluidity increased firstly and then decreased, the value reached the top point when the IOTP specific surface area was $588 \mathrm{~m} 2 / \mathrm{kg}$. On the whole, the work performance of UHPC could be improved through mixing right amount of IOTP.

\section{Pore structure}

Figure 3 was about the influence of IOTP content on pore structure when the IOTP specific surface area was $801 \mathrm{~m} 2 / \mathrm{kg}$. We could see that both the hole size-volume and hole size-area showed the same changing rule. The pore size distribution was the best when the replacing content was $5 \%$, when the dosage increased to $10 \%$, although the pore area and pore volume increased, but still lower than the standard sample. But when IOTP content increased to $15 \%$, pore area and pore volume became further coarsening, value is greater than the standard sample. It showed the same law as strength, IOTP had enhancement effect to the strength when IOTP replacement content did 
not exceed $10 \%$, when the replacement amount was $15 \%$, IOTP had negative effect on strength and pore structure.

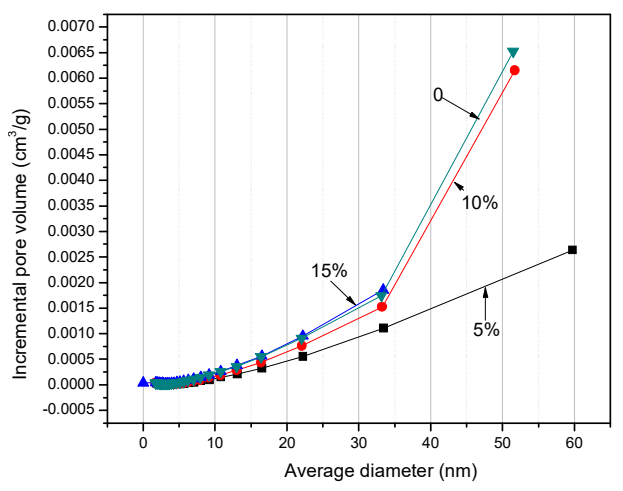

(a) Pore size-volume

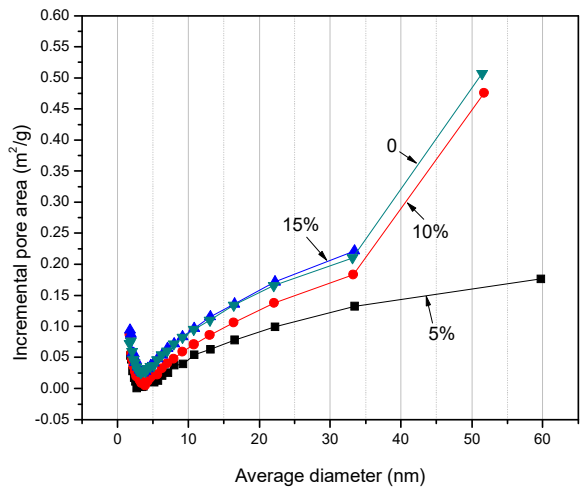

(b) Pore size-area

\section{Morphology}

Fig.3 The influence of cement replacement content on pore size distribution

Figure 4 was about the influence of IOTP content on hydration products morphology when the IOTP specific surface area was $801 \mathrm{~m} 2 / \mathrm{kg}$. . CSH gel in figure (a) was evenly distributed, we could see some un-hydrated round particles, mainly for the beads, fly ash and silica fume.CSH gel distribution in figure (b) was not equal to standard sample, but for aggregate the wrapping effect was very good, it did not see obvious interface transition zone. With rod material in figure (c), there were some $\mathrm{Ca}(\mathrm{OH}) 2$ at the lower right corner which between aggregate and $\mathrm{CSH}$ gel, at the same time, there was a crack at the lower left part of the picture. $\mathrm{CSH}$ gel in figure (d) was obvious thinner than the other three images, a clear crack almost throughout $1 / 3$ length of the picture and more $\mathrm{Ca}(\mathrm{OH}) 2$.

With the increase of IOTP replacing cement, the hydration products content and compactness of CSH gel would be worse. However, considering the strength, liquidity and pore size distribution, when the content was no more than $10 \%$, it could improve the properties of UHPC, this is mainly because average particle size of IOTP was smaller than the cement particles, it played a better physical filling effect for UHPC and strengthen the "core effect". However, when the IOTP was too much (H particles increased and L particles decreased), with a certain porosity, the gel reduced to a certain degree $(\mathrm{H} / \mathrm{L}$ ratio to a certain degree), $\mathrm{L}$ particles could not fill the porosity of $\mathrm{H}$ particles which would lead to strength reduced.

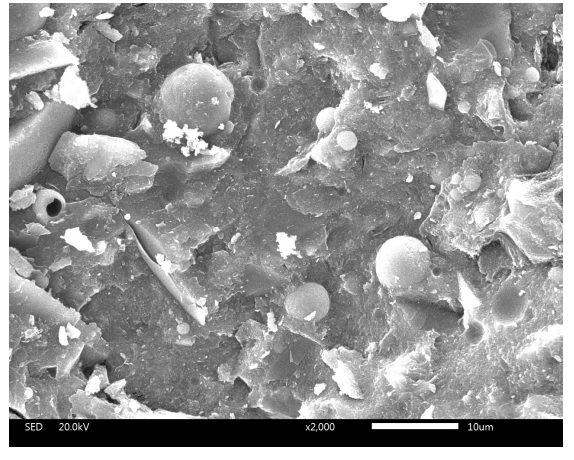

(a) Standard

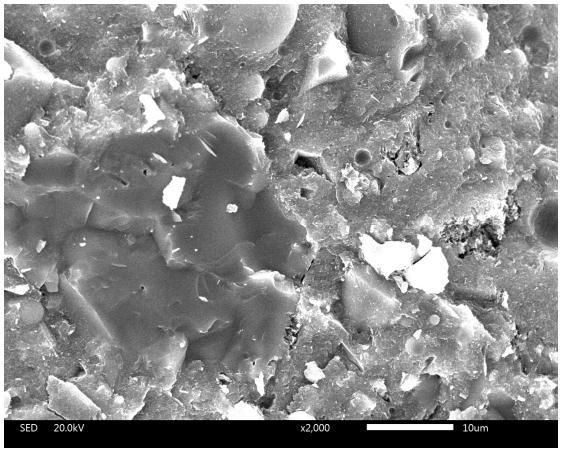

(b) $5 \%$ 


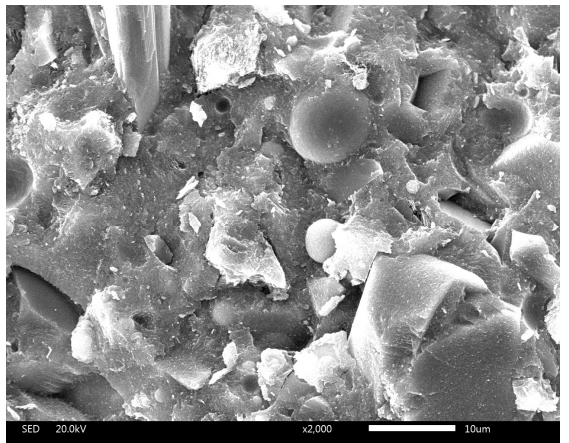

(c) $10 \%$

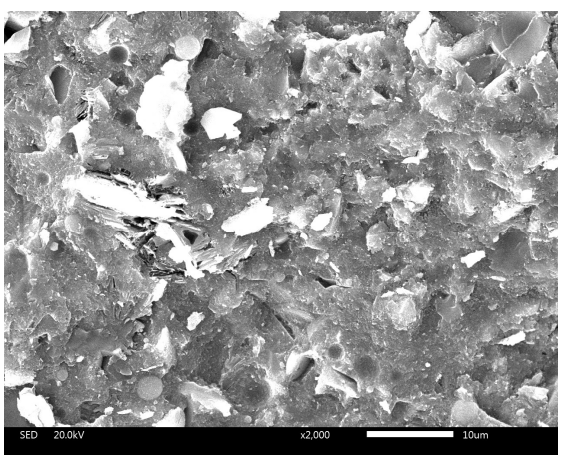

(d) $15 \%$

Fig.4 The influence of cement replacement content on SEM patterns

\section{Conclusions}

From the above research, it can be found that IOTP had a effective interaction on UHPC when cement replaced. When the IOTP content is less than $10 \%$ and controlling specific surface area, the strength, liquidity, pore size distribution and hydration products morphology of UHPC are better than standard samples. Especially, most of these values reach the biggest when the specific surface area of IOTP is $588 \mathrm{~m} 2 / \mathrm{kg}$ or $813 \mathrm{~m} 2 / \mathrm{kg}$. Whereas, when the IOTP is more than $15 \%$, most above properties are worse than standard samples no matter the specific surface area of IOTP.

\section{References:}

[1] Xuefeng WANG. Potential of Synthetical Value in Use of Quadratic Mineral Resources is Huge. CONSERVATION AND UTILIZATION OFMINERAL RESOURCES, 2008(1):56-58.

[2] Luis M, Ivars N. Long-term Environmental Impact of Tailings Deposits. Hydrometallurgy, 2006,83:176-183.

[3] Rico M, Benito G, Díez-Herrero A. Floods from Tailing Dam Failures. J Hazard Mater,2008(154):79-87.

[4] Passarielloa B, Giulianoa V, Quaresimaa S,et al. Evaluation of the Environmental Contamination at an Abandoned Mining Site. Microchem J, 2002(73):245-250.

[5] Martín F, García I,Díez M, et al. Soil Alteration by Continued Oxidation of Pyrite Tailings. Appl Geochem, 2008(23):1152-1165.

[6] Jia LIU, Wen NI, Miao YU. Hydration characteristics and paste structure of complex cementitious material containing high-volume iron ore tailings powder. The fifth conference on comprehensive utilization of tailings and metallurgical slag technology, 2014, 17-24.

[7] Xueying MA, Application of Siliceous Iron Tail Mineral Powder as Concrete Admixture. Tsinghua University, 2013.

[8] Mengyi CHEN, Beixing LI, Wei WANG, Zhigang ZHU. Reactive Activity of Iron Tailings Powder and its Enhancement Effect upon Concrete. METAL MINE, 2013(05),164-168.

[9] Xiaoyan HUANG, Wen NI, Keqing LI. Development of engineered cementitious composites containing iron ore tailing powders, Chinese Journal of Engineering, 2015, 37(11), 1491-1497.

[10] Richard Pieer, Cheyrezy Marcel. Composition of reactive powder concrete. Cement and Concrete Research, 1995, 25(7): 1501-1511. 
[11] M. Cheyrezy, V. Maret, L. Frouin. Microstructural Analysis of RPC (Reactive Powder Concrete). Cement and Concrete Research. 1995, 25(7): 1491-1500.

[12] Philippot S, Korb J P, Petit D, et al. Analysis of microporosity and setting of reactive powder concrete by Proton nuclear relaxation. Magnetic Resonance Imaging, 1998, 16(5-6): 515-519.

[13] Huisheng SHI, Tao SHI, Baochun CHEN. Research of Chloride Ion Diffusivity in Reactive Powder Concrete with Blast-Furnace Slag. JOURNAL OF TONGJI UNIVERSITY (NATURAL SCIENCE), 2006, 34(1):93-96.

[14] Tao SHI. STUDY ON THE REACTIVE POWDER CONCRETE WITH BLAST FURNACE SLAG AND IT' S HIGH DURABILITIES. Hangzhou: Zhejiang University of Technology, 2004.

[15] Kaizhan KE. Research on the basic mechanical properties of the fiber reactive powder concrete and application. Fuzhou:Fuzhou University, 2005. 